\title{
Multi-instrument mapping of the small-scale flow dynamics related to a cusp auroral transient
}

\author{
K. Oksavik ${ }^{1,2}$, J. Moen ${ }^{1,3}$, H. C. Carlson ${ }^{4}$, R. A. Greenwald ${ }^{2}$, S. E. Milan ${ }^{5}$, M. Lester ${ }^{5}$, W. F. Denig ${ }^{6}$, and R. J. Barnes ${ }^{2}$ \\ ${ }^{1}$ Department of Physics, University of Oslo, Oslo, Norway \\ ${ }^{2}$ Applied Physics Laboratory, Johns Hopkins University, Laurel, Maryland, USA \\ 3 also at: Arctic Geophysics, University Centre on Svalbard, Longyearbyen, Norway \\ ${ }^{4}$ Air Force Research Laboratory, AFOSR/CA, Arlington, Virginia, USA \\ ${ }^{5}$ Department of Physics and Astronomy, University of Leicester, Leicester, UK \\ ${ }^{6}$ Space Vehicles Directorate, Air Force Research Laboratory, VSBXP, Hanscom AFB, MA, USA
}

Received: 30 August 2004 - Revised: 22 July 2005 - Accepted: 10 August 2005 - Published: 14 October 2005

\begin{abstract}
In this paper we focus on flux transfer events (FTEs) and poleward moving auroral forms (PMAFs) in the cusp region, combining data from the EISCAT Svalbard radar, SuperDARN HF radars, ground-based optics, and three low-altitude polar-orbiting spacecraft. During an interval of southward interplanetary magnetic field the EISCAT Svalbard radar tracked a train of narrow flow channels drifting into the polar cap. One $30-60 \mathrm{~km}$ wide flow channel surrounded by flow running in the opposite direction is studied in great detail from when it formed equatorward of the cusp aurora, near magnetic noon, until it left the field-of-view and disappeared into the polar cap. Satellite data shows that the flow channel was on open field lines. The flow pattern is consistent with field-aligned currents on the sides of the flow channel; with a downward current on the equatorward side, and an upward current on the poleward side. The poleward edge of the flow channel was coincident with a PMAF that separated from the background cusp aurora and drifted into the polar cap. A passage of the DMSP F13 spacecraft confirms that the FTE flow channel was still discernable over 15 minutes after it formed, as the spacecraft revealed a 30$40 \mathrm{~km}$ wide region of sunward flow within the anti-sunward background convection. From the dimensions of the flow channel we estimate that the magnetic flux contained in the event was at least $1 \mathrm{MWb}$. This data set also shows that Birkeland current filaments often seen by low-altitude spacecraft in the cusp/mantle are really associated with individual FTE events or a train of FTEs in progress. As the region 0 or cusp/mantle current represents the statistical average consistent with the large-scale flow pattern, we therefore introduce a new term - FTE currents - to denote the unique pair of Birkeland current sheets that are associated with individual meso-scale FTE flow disturbances. The poleward moving
\end{abstract}

Correspondence to: K. Oksavik

(kjellmar.oksavik@jhuapl.edu) auroral forms (PMAFs), often referred to in the literature, are the optical signature of the upward FTE current.

Keywords. Magnetospheric physics (Current systems; Magnetopause, cusp and boundary layers) - Ionosphere (plasma convection)

\section{Introduction}

In a recent paper Oksavik et al. (2004a) demonstrated how the EISCAT Svalbard radar can be used to monitor smallscale flow structures in the polar ionosphere within a large field-of-view. Their technique was used to resolve the flow pattern surrounding a single poleward moving auroral form (PMAF), an optical signature in the cusp ionosphere that is believed to be the visible signature of flux transfer events (FTEs). Oksavik et al. interpreted their observations as supporting experimental evidence for the Southwood (1985, 1987) model, which predicts a twin-vortex flow pattern surrounding the footprint of the FTE, flux tube. Birkeland currents are fed along the flanks of the flux tube transferring stress from interplanetary space (Southwood and Hughes, 1983) and set the ionospheric foot of the flux tube in motion (Southwood, 1987). In the ionosphere the currents close horizontally through Pedersen currents parallel to the convection electric field. Oksavik et al. (2004a) observed that the PMAF was located on the poleward edge of the FTE flow channel, where the field-aligned Birkeland current is flowing out of the ionosphere. A similar conclusion was reached by Milan et al. (2000).

One major question during the last couple of decades has been whether magnetic reconnection is continuous (quasisteady) or pulsed (impulsive) (Haerendel et al., 1978; Russell and Elphic, 1978, 1979). The primary transfer mechanism of flux from the solar wind to the magnetosphere is believed 
to be impulsive dayside reconnection, also called FTEs (e.g. Cowley and Lockwood, 1992; Lockwood et al., 1995). Transient events in the high-latitude ionosphere are often associated with bursts in the reconnection rate (e.g. Lockwood et al., 2003) ${ }^{1}$, and Moen et al. (1995) were the first to observe simultaneous pulsed return flow of the dawn and dusk convection cells in association with cusp auroral transients. At the magnetopause FTE signatures often have a scale size of one Earth radius in the boundary normal direction (Saunders et al., 1984). In the ionosphere this will correspond to around 100-200 km along the meridian (Southwood, 1985, 1987). A reconnection burst is communicated from the magnetopause to the ionosphere as an Alfvénic disturbance with an associated system of field-aligned currents (FACs) (Glassmeier and Stellmacher, 1996).

From the ground the first radar observations of FTEs were carried out by van Eyken et al. (1984) and Goertz et al. (1985). Provan et al. $(1998,2002)$ observed pulsed transients in the plasma flow poleward of the convection reversal boundary, and Neudegg et al. (2000) found good correspondance between FTEs near the magnetopause and discrete flow channels in the ionosphere. Signatures of FTEs have also been identified as poleward moving transients in the dayside aurora (e.g. Sandholt et al., 1990, 1993; Denig et al., 1993; Milan et al., 1999a, 2000; Thorolfsson et al., 2000; Moen et al., 2001a). In HF radar backscatter quite a few examples of poleward moving transients have been reported, and depending on their unique characteristics, these cases have been termed: flow channel events (FCE) (Pinnock et al., 1993, 1995; Chisham et al., 2000; Neudegg et al., 1999, 2000), pulsed ionospheric flows (PIFs) (Provan et al., 1998, 2002; Provan and Yeoman, 1999; McWilliams et al., 2000), or poleward moving radar auroral forms (PMRAFs) (Milan et al., 2000; Davies et al., 2002; Rae et al., 2004). These features are also often related to each other (Wild et al., 2001), and dayside transients typically show repetition rates (e.g. Milan et al., 1999a) comparable to that of FTEs at the magnetopause.

In this paper we present a uniquely comprehensive set of observations of an FTE and its evolution from a variety of instruments. Convection data from the SuperDARN HF radar network gives information on the large-scale background flow, the EISCAT Svalbard radar in a fast scan mode gives high-resolution observations of the small-scale plasma flow surrounding the PMAF transient, a low-altitude polar orbiting DMSP spacecraft intersects the transient on its way across the polar cap, and two low-altitude polar orbiting NOAA spacecraft confirm that the aurora and the auroral transient are all located on open magnetic field lines.

\footnotetext{
${ }^{1}$ Lockwood, M., Davies, J. A., Moen, J., van Eyken, A. P., Oksavik, K., McCrea, I. W., and Lester, M. E.: Motion of the dayside polar cap boundary during substorm cycles: II. Generation of poleward-moving events and polar cap patches by pulses in the magnetopause reconnection rate, Ann. Geophys., submitted, 2003.
}

\section{Instrumentation}

The EISCAT Svalbard Radar (ESR) is located at Longyearbyen $\left(78.15^{\circ} \mathrm{N}, 16.03^{\circ} \mathrm{E}\right)$, corresponding to $75.1^{\circ}$ magnetic latitude. The radar consists of two parabolic antenna systems; a fully steerable $32-\mathrm{m}$ dish and a fixed $42-\mathrm{m}$ dish pointing along the magnetic field. On 18 December 2001 only the steerable dish was used, to move the radar beam in a fast azimuth scan. Sweeping continiously at fixed elevation $\left(30^{\circ}\right)$ between two azimuth extremes $\left(180\right.$ and $\left.300^{\circ}\right)$ at a speed of $0.625^{\circ} \mathrm{s}$, a plot of the line-of-sight ion drift within the fanshaped field-of-view was obtained every $192 \mathrm{~s}$, alternating between clockwise and anticlockwise scans. During a scan data is stored every $3.2 \mathrm{~s}$, giving 60 adjacent beam directions that are $2^{\circ}$ wide in azimuth. The radial resolution (line-ofsight) is around $40 \mathrm{~km}$, and depending on the distance from the radar site, the resolution in azimuth is between 10 and $30 \mathrm{~km}$. This is a type of scan that has previously been used by Carlson et al. $(2002,2004)$ and Oksavik et al. (2004a).

Ground-based optical observations from Ny-Ålesund, Svalbard, were from the all-sky camera of the Air Force Research Laboratory (AFRL) and the all-sky camera and meridian scanning photometer (MSP) of the University of Oslo (UiO). The MSP measured auroral emissions at two wavelengths $(557.5$ and $630.0 \mathrm{~nm})$, scanning north to south, approximately along the magnetic meridian. The AFRL camera obtained images of the 557.7-nm and 630.0-nm lines, every 60 and $30 \mathrm{~s}$, respectively. The UiO camera obtained images at the 630.0-nm line, every $30 \mathrm{~s}$. The all-sky images are truncated at $70^{\circ}$ zenith angle and superimposed onto a local geographic map, assuming an emission altitude of $250 \mathrm{~km}$ for the $630.0 \mathrm{~nm}$ line, and $200 \mathrm{~km}$ altitude for the $557.7 \mathrm{~nm}$ line. Our reason for choosing $200 \mathrm{~km}$ for the green line is that in the cusp the particle fluxes are soft and this altitude gives a better overall correspondence with the location of the red line features after the aurora has been projected onto the map. A similar conclusion has been made by Milan et al. (1999b).

The two CUTLASS (Co-operative UK Twin Located Auroral Sounding System) radars are located at Hankasalmi, Finland, $\left(62.32^{\circ} \mathrm{N}, 26.61^{\circ} \mathrm{E}\right)$, and Rykkvibær, Iceland, $\left(63.86^{\circ} \mathrm{N}, 19.20^{\circ} \mathrm{W}\right)$. Both radars are part of the SuperDARN radar network (Greenwald et al., 1995) and can operate at frequencies between 8 and $20 \mathrm{MHz}$ in the HF band. These radars measure coherent backscatter echoes from field-aligned plasma irregularities in the high-latitude ionosphere. Each radar forms an antenna pattern with 16 azimuthal pointing directions (hereafter called beams), separated by $3.2^{\circ}$. According to the theoretical calculations of Greenwald et al. (1985), the two-way half-power beam width depends on the transmitter frequency and varies from $2.5^{\circ}$ at $20 \mathrm{MHz}$ to $6^{\circ}$ at $8 \mathrm{MHz}$. On 18 December 2001 the transmitter frequency for both CUTLASS radars was 12.2 $12.4 \mathrm{MHz}$, corresponding to beam widths of $4.7-4.8^{\circ}$. For CUTLASS the field-of-view includes Svalbard, whenever the ionospheric conditions for radio wave propagation are favourable. To receive ionospheric backscatter over Svalbard the propagation mode most likely is the $1.5 \mathrm{~F}$ mode of 
HF radio wave propagation (Milan et al., 1997), and studies have shown that the cusp region and dayside auroral oval behave like a hard target (Milan et al., 1998; Moen et al., 2001b). Transmitting a 7-pulse scheme and analyzing the autocorrelation function of the returning signals gives backscatter Doppler spectra. These spectra are used to derive spectral characteristics, such as power, line-of-sight velocity and spectral width (e.g. Hanuise et al., 1993; Baker et al., 1995). In the F-region the backscattered echo is a trace of the $\mathbf{E} \times \mathbf{B}$ plasma drift (Villain et al., 1985; Ruohoniemi et al., 1987; Davies et al., 1999, 2000). The data we present was recorded in 70 range intervals of $45 \mathrm{~km}$ length between 180 and $3330 \mathrm{~km}$ from the two radar sites. For both radars each beam direction was sampled for $3 \mathrm{~s}$, and a new sequence stepping through all 16 beam directions was started every $60 \mathrm{~s}$. Within the ESR field-of-view the spatial resolution is expected to be $45 \mathrm{~km}$ north/south and $150-200 \mathrm{~km}$ east/west for the Finland radar, and 150-200 km north/south and $45 \mathrm{~km}$ east/west for the Iceland radar. For comparison the ESR data resolution is around $40 \mathrm{~km}$ line-of-sight and $10-30 \mathrm{~km}$ in azimuth (depending on the distance from the radar site).

The DMSP F13 spacecraft flies in a Sun-synchronous circular polar orbit at an altitude of $840 \mathrm{~km}$. The instrumentation on DMSP F13 includes energetic particle spectrometers (Hardy et al., 1984), an ion drift meter (IDM) (Rich and Hairston, 1994), and a tri-axial magnetometer. The particle spectrometers on DMSP F13 look toward local zenith to measure fluxes of electrons and ions with energies between $30 \mathrm{eV}$ and $30 \mathrm{keV}$, once per second, in 20 logarithmically spaced steps. The IDM measures the horizontal and vertical components of the plasma flow across the trajectory. The horizontal drift (after correcting for the Earth's co-rotation) is driven by the along-track component of the electric field $\mathbf{E}$, which is calculated using the "frozen-in-flux" condition $\mathbf{E}=-\mathbf{v} \times \mathbf{B}$, where $\mathbf{v}$ and $\mathbf{B}$ represent the ion drift and the magnetic field, respectively. The magnetometer measures the full vector field 12 times per second over the range $\pm 68000 \mathrm{nT}$ with a resolution of $2 \mathrm{nT}$. Data are presented as differences between actual component measurements and predictions of the International Geophysical Reference Field model IGRF 2000 (Mandea and Macmillan, 2000).

The NOAA spacecraft are operated by the National Oceanic and Atmospheric Administration in low-altitude Sun-synchronous circular polar orbits. NOAA-15 crosses the northern cusp region from east to west at an altitude of $824 \mathrm{~km}$, whilst NOAA-16 crosses the northern cusp region from south to north at an altitude of $866 \mathrm{~km}$. Both spacecraft have similar instrumentation, and the present study uses observations of electrons and protons from the Total Energy Detector (TED) and the Medium Energy Proton and Electron Detector (MEPED) instruments. TED measures electrons and ions in 16 energy channels between 0.05 and $20 \mathrm{keV}$ at two viewing directions; one looks toward local zenith, the other looks $30^{\circ}$ from zenith. Fluxes observed at both look angles are well within the atmospheric loss cone. The TED instrument was primary designed to obtain particle energy flux moments, but it can also provide crude electron and

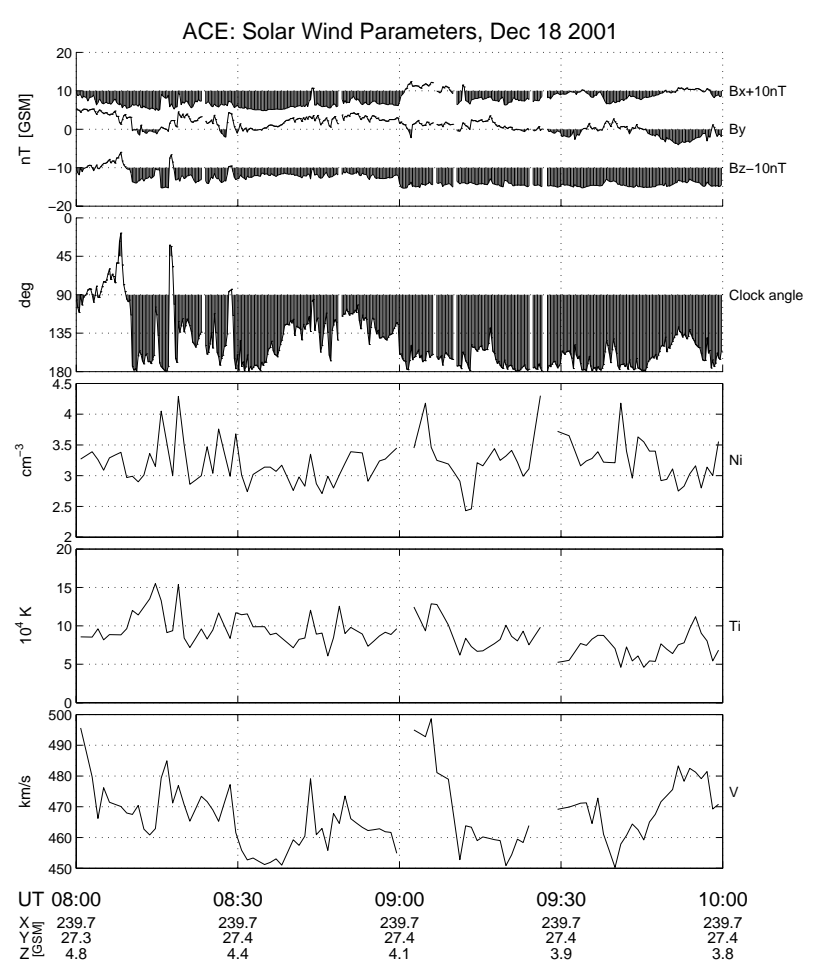

Fig. 1. Interplanetary magnetic field and solar wind parameters from the ACE spacecraft. The panels show from the top: the three components of the interplanetary magnetic field (negative values indicated with shading), the clock angle of the interplanetary magnetic field $\left(>90^{\circ}\right.$ or southward field indicated with shading), the solar wind ion density $(\mathrm{Ni})$, the solar wind ion temperature (Ti), and the solar wind velocity (V).

ion spectra. The MEPED instrument measures protons and electrons at angles of 10 and $80^{\circ}$ to the local vertical, corresponding to precipitating and trapped particles in the auroral zone, respectively. Observations from one proton channel $(30-80 \mathrm{keV})$ and one electron channel $(>30 \mathrm{keV})$ are used in this study. A detailed description of the NOAA spacecraft and the particle instrumentation is given by Evans and Greer (2000).

Solar wind parameters were obtained from the ACE spacecraft (Chiu et al., 1998) located near the L1 point in the solar wind upstream of the Earth. On 18 December 2001, the position of the spacecraft was $(240,27,4) R_{E}$ in GSM coordinates. For this paper we focus on data from the ACE magnetic fields experiment (Smith et al., 1998) and the Solar Wind Electron Proton Alpha Monitor (SWEPAM) (McComas et al., 1998).

\section{Observations}

Figure 1 presents an overview of the solar wind parameters from the ACE spacecraft (please note that the data points have not been lagged). The solar wind density and temperature were rather constant, with a solar wind velocity of 


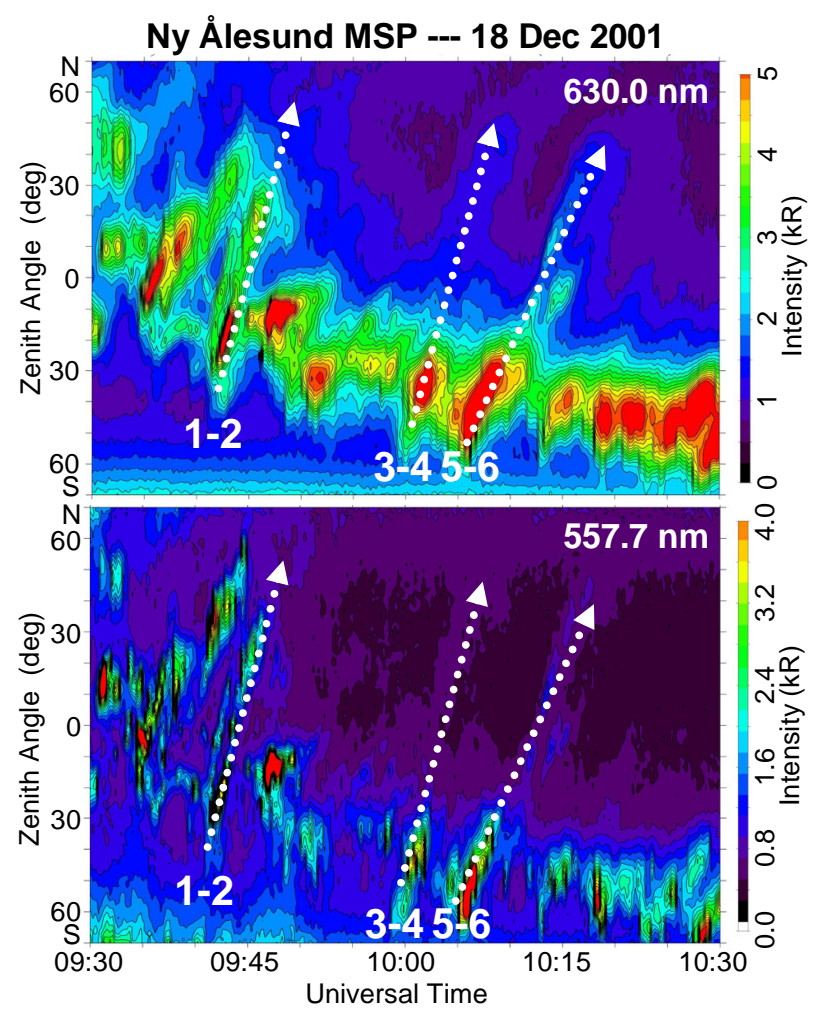

Fig. 2. Meridian scanning photometer data from Ny-Ålesund, Svalbard. The upper panel shows the recorded intensities for the 630.0$\mathrm{nm}$ (red line) and the lower panel the 557.7-nm (green) line. White dotted lines indicate three poleward moving auroral forms (1-2, 3$4,5-6)$ that occurred between the respective flow channels identified in Fig. 3.

$450-500 \mathrm{~km} / \mathrm{s}$, and the clock angle indicates that the IMF had a significant southward component. The IMF $B_{x}$ was mainly negative, $B_{y}$ was generally positive, and $B_{z}$ was $-3 \mathrm{nT}$ prior to 09:00 UT, whereafter there is a step to $-5 \mathrm{nT}$. An expected propagation delay of around 50-55 min means that this increase in the southward component will reach the magnetopause near 09:45 UT. Even though this estimate is only based on the time it takes for the solar wind to travel a radial distance of $240 R_{E}$, the timing appears to be consistent with observed changes in the ground-based data.

Figure 2 shows a one-hour overview of the MSP recordings from Ny-Ålesund, Svalbard. The upper panel shows the $630.0 \mathrm{~nm}$ (red line), and the lower panel the $557.7 \mathrm{~nm}$ (green line). Throughout the time interval (and in particular, starting around 09:45 UT) the aurora migrated equatorward within the MSP field-of-view, and all-sky images (not shown) confirm that this is consistent with a general equatorward shift of the cusp aurora. The equatorward motion is assumed to be due to enhanced reconnection from an increased southward IMF. The aurora was also pulsed in intensity. Each brightening is separated by $5-10 \mathrm{~min}$, and most brightenings are seen both in the red and green lines. The auroral brightening associated with three poleward moving form events $(1-2,3-$ 4, and 5-6) is indicated in Fig. 2 with white dotted arrows.
Due to the comprehensive instrumental coverage, later in this paper we will be paying special attention to the feature identified as PMAF event 3-4.

Figure 3 gives an overview of the plasma flow observations from the EISCAT Svalbard radar (ESR). The ESR 32-m dish was scanning back and forth in azimuth at low elevation, looking west of Svalbard, and the observations show how the radar line-of-sight plasma flow evolved as a train of east-west flow channels drifted into the polar cap. Around 09:45 UT a westward flow channel (hereafter called FC2) was observed northwest of Svalbard. FC2 had an area of eastward flow on its poleward side; hereafter this flow area is identified as FC1. Both $\mathrm{FC} 1$ and $\mathrm{FC} 2$ drifted poleward and were followed by an eastward flow channel FC3. As indicated in Fig. 3, the first clear signature of FC3 was seen around 09:47 UT before it grew stronger around 09:50 UT. At 09:56 UT two more flow channels, FC4 and FC5, were seen equatorward of FC3, and FC2 reached poleward of the field-of-view around 09:58 UT. FC3, FC4 and FC5 also drifted poleward, and became clearly identified features around 10:03 UT. At 10:10 UT FC3 had left poleward of the ESR field-of-view, and a new channel FC6, of westward flow was born equatorward of FC5. By 10:17 UT FC4 had also reached poleward of the field-ofview, FC5 became weaker, and a new eastward flow channel FC7 was formed equatorward of FC6.

The alternation between towards and away velocities is an indication of small vortices in the plasma flow, as predicted by the Southwood (1987) model and supported by observations of Oksavik et al. (2004a). As the FTE flux tube is moving into the polar cap, plasma inside the perimeter of the flux tube is moving in one direction, consistent with a flow channel. Due to the incompressibility of the ionosphere, plasma surrounding the fast-moving flux tube will be pushed away, to the sides, and eventually will close in behind the FTE flux tube, forming one vortex on each side of the flow channel. Consequently, for a single FTE event there will be three flow channels; one flow channel of enhanced flow within the perimeter of the FTE flux tube (like FC4), and two flow channels of reduced or return flow on the sides of the flow channel (like FC3 and FC5). These are all predictions of the Southwood (1987) model. On its poleward boundary FC4 has a velocity reversal driving an outgoing current and a precipitation of electrons which will excite an optical auroral feature identified as 3-4 in Fig. 2. The flow reversal on the equatorward boundary of FC4 has an associated downward current. All of these boundaries drift poleward with time, as they persist in time. For consistency it should also be noted that optical features will exist on the poleward boundary of FC2 (i.e. PMAF event 1-2 in Fig. 2) and FC6 (i.e. PMAF event 5-6 in Fig. 2), however, the remainder of the paper will focus on the characteristics of PMAF event 3-4 and the associated flow channels FC3, FC4, and FC5.

In Figs. 4 and 5 we present all-sky images of the aurora during this event for the auroral lines $630.0 \mathrm{~nm}$ and $557.7 \mathrm{~nm}$, respectively. These images are from the high-gain AFRL camera at Ny-Ålesund, Svalbard. The 630.0-nm images are projected to $250 \mathrm{~km}$ altitude and the $557.7-\mathrm{nm}$ images to 



Fig. 3. Ion flow observations from a sequence of fast windshield wiper scans of the EISCAT Svalbard Radar. The radar was scanning back and forth in azimuth to the west of Svalbard, and shown with colors is the radar line-of-sight plasma flow, where red corresponds to drift away from the radar and blue is towards the radar. Identified with numbers are seven flow channels, see text for details.

$200 \mathrm{~km}$ altitude. Indicated with a white arrow is the PMAF that appeared around 10:02 UT and drifted north toward the polar cap, as seen in both the 630.0 and $557.7 \mathrm{~nm}$ images. The PMAF was most intense around 10:03-10:05 UT, with intensities reaching above $1 \mathrm{kR}$ in 630.0-nm and around $0.7 \mathrm{kR}$ in $557.7 \mathrm{~nm}$. The PMAF was visible in $557.7-\mathrm{nm}$ (Fig. 5) until 10:09 UT, when the intensity went below the camera threshold of $0.2 \mathrm{kR}$. In $630.0 \mathrm{~nm}$ (Fig. 4) the PMAF could be followed at least until 10:10 UT, when the DMSP F13 spacecraft entered the field-of-view. The mapped trajectory is shown in Fig. $6 \mathrm{f}$.

Data from the DMSP F13 is presented in Fig. 6. Figures 6a and $b$ are energy-versus-time spectrograms for electrons and ions. Following the Newell and Meng (1992) classification 


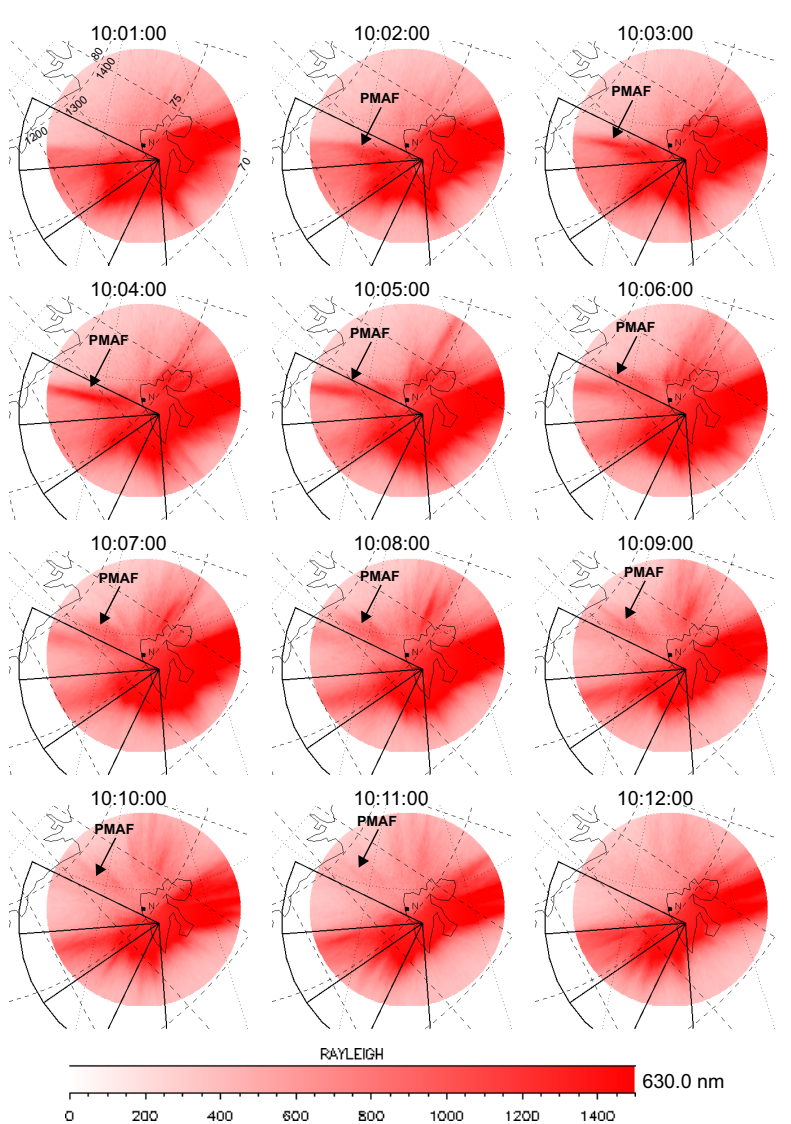

Fig. 4. Sequence of 630.0-nm (red line) all-sky images from the Ny-Ålesund AFRL camera showing the motion of the PMAF. The images are overlaid on a magnetic grid, and shown with solid lines is the EISCAT Svalbard radar's field-of-view.

scheme, the post-noon BPS was crossed from 10:06:0410:08:05 UT, the pre-noon LLBL/BPS from 10:13:5010:15:11 UT, followed by the pre-noon CPS from 10:15:1210:18:17 UT. In the time interval the spacecraft is within the all-sky field of view, it is also within the dayside polar cap (between the pre-noon BPS and the post-noon LLBL/BPS encounters). Figure $6 \mathrm{c}$ depicts the vertical (VER; green curve) and horizontal cross-track (HOR-C; purple curve) components of the plasma drift measured by the IDM. Positive values of the purple curve correspond to a mostly sunward drift, i.e. on a gross scale the plasma is drifting sunward in the pre-noon and post-noon BPSs, and anti-sunward into the polar cap within the all-sky camera field-of-view consistent with a standard twin-cell southward IMF convection pattern. Figure $6 \mathrm{~d}$ plots components of the perturbation magnetic field in a spacecraft-centered coordinate system, where the perturbation is the difference between the value measured by the onboard tri-axial magnetometer and the IGRF model. The DBY component (light blue curve) points horizontal in a direction nearly parallel with the spacecraft's velocity vector, and the DBZ component (red curve) points horizontal and perpendicular to the spacecraft trajectory. For

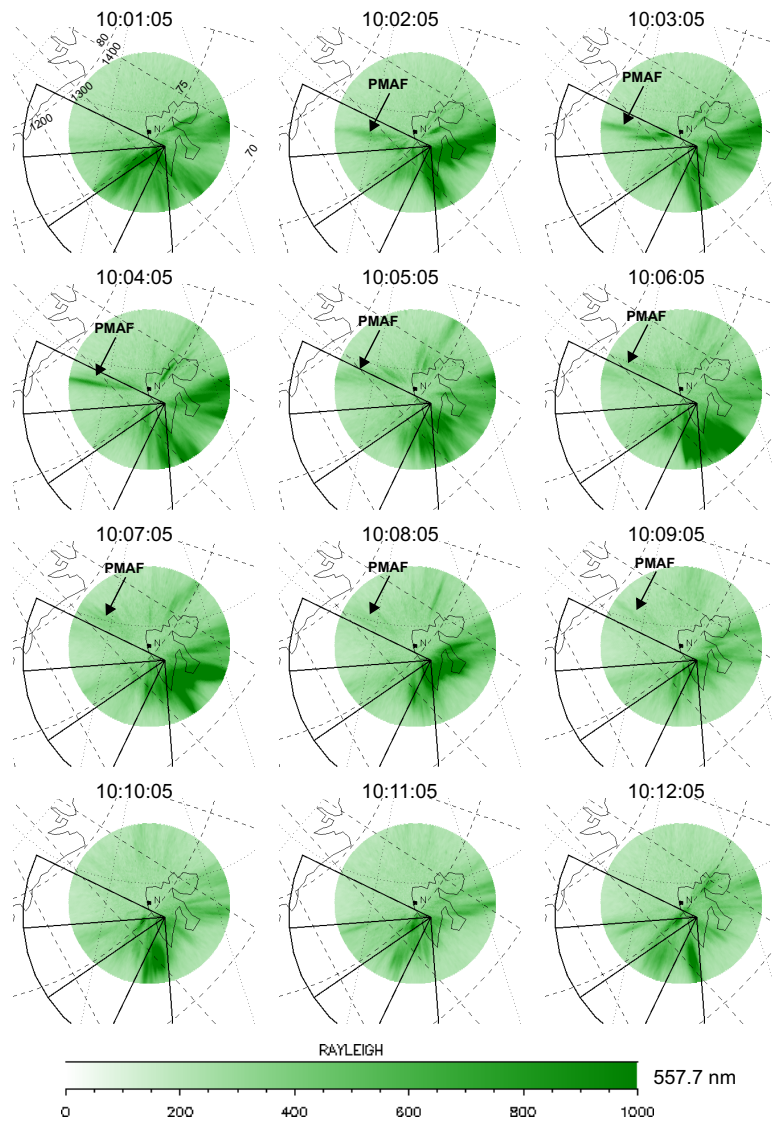

Fig. 5. Sequence of 557.7-nm (green line) all-sky images from the Ny-Ålesund AFRL camera showing the motion of the PMAF. The images are overlaid on a magnetic grid, and shown with solid lines is the EISCAT Svalbard radar's field-of-view.

the red curve positive slopes correspond to Birkeland currents into the ionosphere. Consequently, one can see the encounter with the post-noon region 2 current flowing into the ionosphere around 10:05 UT, the post-noon region 1 current flowing out of the ionosphere around 10:07 UT, and the pre-noon region 1 current flowing into the ionosphere from 10:14-10:15 UT. Figure 6e is an enlargement of the horizontal cross-track plasma drift component in Fig. 6c, showing the narrow region in the polar cap of sunward flow around 10:11 UT. In Fig. 6f the DMSP F13 trajectory has been overlaid onto an image of the 630-nm cusp aurora (from the AFRL camera in Ny-Ålesund), showing how the spacecraft was located north of the cusp aurora as it traveled from east to west.

To complement the DMSP observations, in Fig. 7 we present particle data from the NOAA 15 and 16 spacecraft. Figures 7a and e show data of low-energy precipitating electrons, Figs. $7 \mathrm{~b}$ and $\mathrm{f}$ of energetic electrons, Figs. $7 \mathrm{c}$ and $\mathrm{g}$ of low-energy precipitating ions, and Figs. $7 \mathrm{~d}$ and $\mathrm{h}$ of energetic ions. In panels $7 \mathrm{~b}, \mathrm{~d}, \mathrm{f}$ and $\mathrm{h}$ the solid and dashed curves represent particles with a pitch angle near $10^{\circ}$ (i.e. precipitating particles) and near $80^{\circ}$ (i.e. local mirroring particles), 


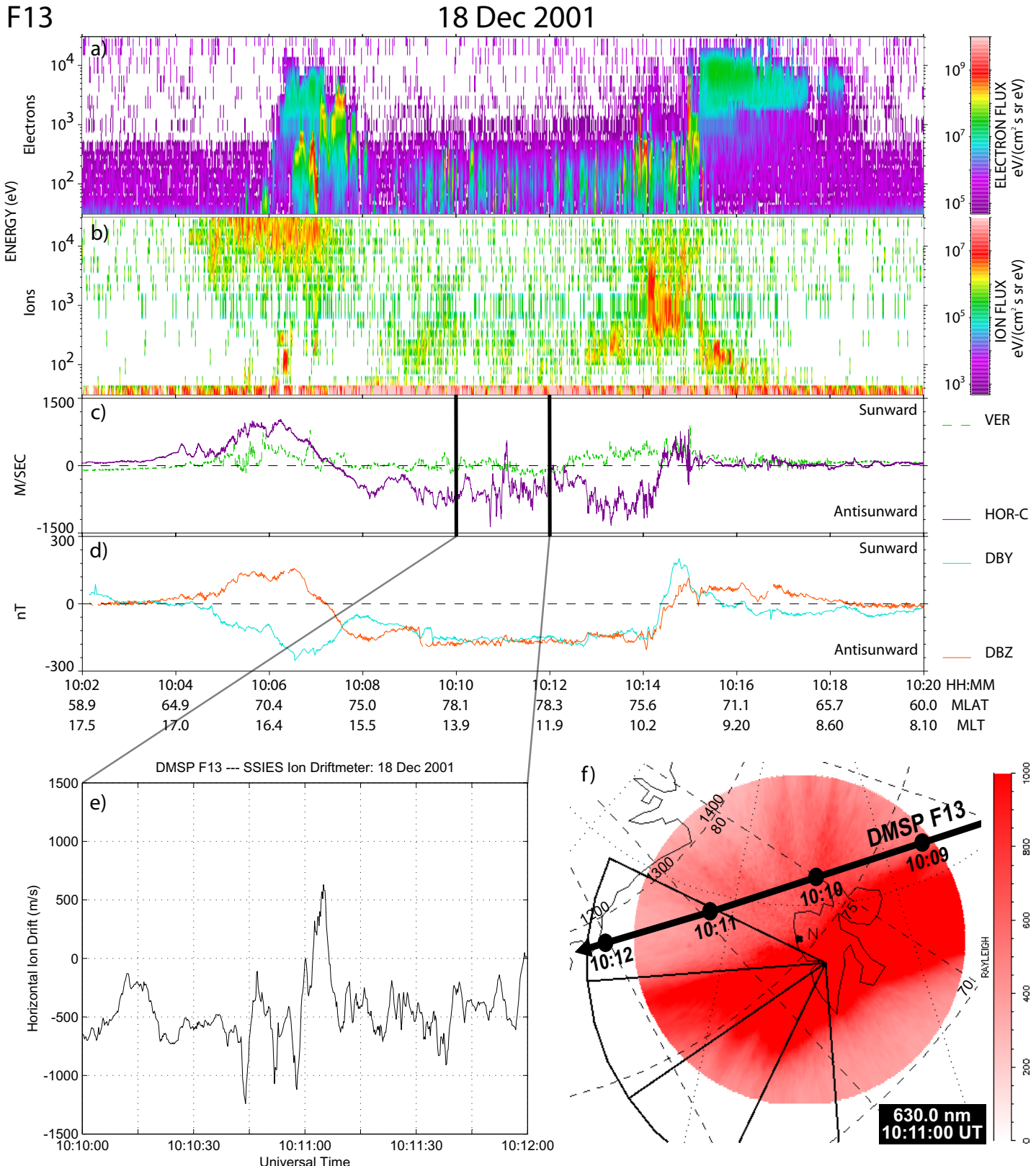

Fig. 6. Observations from the DMSP F13 spacecraft and the trajectory overlaid on the 630-nm cusp aurora. Panels (a) and (b) show energy spectrograms for the electron and ion precipitation. Panel (c) plots the vertical (green curve) and horizontal cross-track (purple curve) components of the plasma drift. Panel (d) plots the DBY (light blue curve) and DBZ (red curve) components of the perturbation magnetic field, see text for details. Panel (e) is an enlargement of the horizontal component in panel c, revealing a narrow region of sunward flow in the polar cap around 10:11 UT. Panel (f) shows the spacecraft trajectory relative to an image of the 630.0-nm aurora, the magnetic grid, and the EISCAT Svalbard radar's field-of-view.

respectively. In Figs. 7i and j the NOAA 15 and 16 trajectories have been overlaid on images of the $630 \mathrm{~nm}$ cusp aurora (from the AFRL camera in Ny-Ålesund) showing NOAA 15 moving westward and NOAA 16 crossing northward through the midday auroral zone. Indicated with dashed vertical red lines are the time intervals when the two spacecraft were within the camera's field-of-view. NOAA 15 only detected modest fluxes of soft particle precipitation (electrons with en- ergies $<200 \mathrm{eV}$, and ions with energies $<3 \mathrm{keV}$ ) within the camera's field-of-view, consistent with the spacecraft being north of the cusp aurora. NOAA 16 observed a transition from energetic to soft particle precipitation while crossing the $30 \mathrm{keV}$ electron trapping boundary, as indicated with a vertical guide line in Figs. $7 \mathrm{e}-\mathrm{h}$ and a white arrow in Fig. $7 \mathrm{j}$. Please note that the electron trapping boundary (marked by the white arrow and TB in Fig. 7) is located just equatorward 

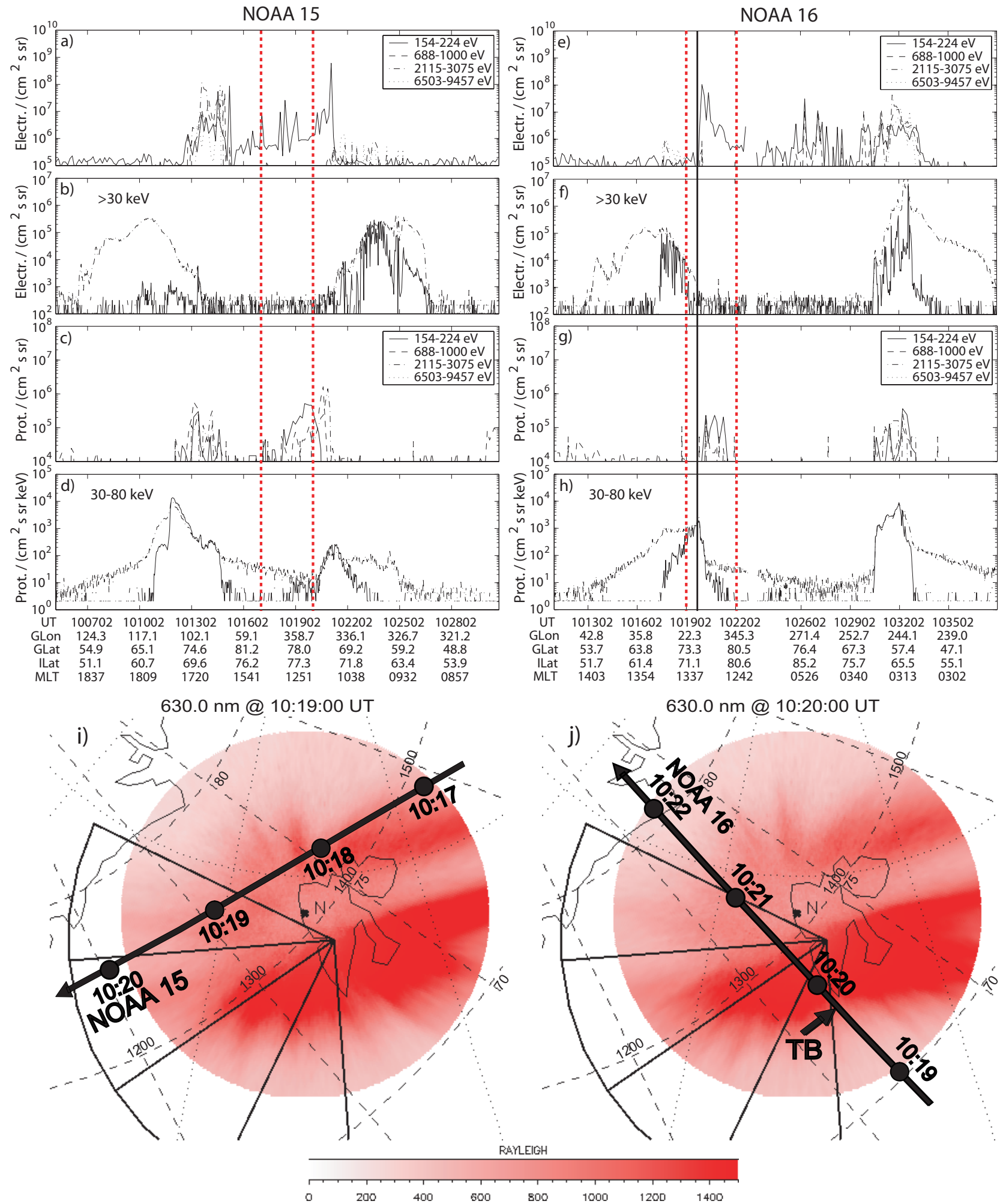

Fig. 7. Particle observations from the NOAA 15 and 16 spacecraft and the two trajectories overlaid on the 630-nm cusp aurora. Panels (a) and (e) show precipitating fluxes from four low-energy electron bands, and panels (c) and (g) from four ion bands. Panels (b) and (f) plot fluxes of energetic electrons, and panels (d) and (h) energetic ions. In these four panels (b, d, f, h) solid lines show precipitating fluxes and dashed lines show local mirroring fluxes. Panels (i) and (j) show the two spacecraft trajectories relative to images of the 630.0-nm aurora, the magnetic grid, and the EISCAT Svalbard radar's field-of-view. In panel $\mathrm{j}$ the electron trapping boundary is indicated with TB. 
of the cusp aurora. Poleward of the electron trapping boundary the electron energies were $<200 \mathrm{eV}$ (number flux decreasing with latitude), and the ion number fluxes were modest for energies $<1 \mathrm{keV}$ and falling off with latitude for energies $>30 \mathrm{keV}$.

\section{Discussion}

The global two-cell convection pattern in the high-latitude ionosphere is believed to be driven by the process of magnetic reconnection (Cowley and Lockwood, 1992). During periods of southward interplanetary magnetic field (IMF), dayside reconnection will produce open flux (Dungey, 1961). This open flux convects over the polar cap and exits by reconnection on the nightside of the magnetosphere. Originally the production, circulation, and removal of magnetic flux in the polar cap were assumed to be steady-state. However, after Russell (1972) sketched the ionospheric flow from a non-steady substorm cycle, dayside and nightside reconnection have come to be viewed as two separate processes, giving non-steady flows in the high-latitude ionosphere. In this paper we focus on the high degree of temporal and spatial variation in the convection that when averaged leads to the standard southward IMF two-cell convection pattern in the cusp region and possibly in the polar cap.

Moen et al. (1995) reported pulsed large-scale convection associated with optical cusp events, and in the last couple of years there have been several studies linking flux transfer events observed by spacecraft near the magnetopause with flow enhancements in the ionosphere. It is also clear that FTEs do occur on many scale sizes. Using the Geotail spacecraft McWilliams et al. (2004) estimated a cross section of 6$7 R_{E}$ for an FTE flux tube near the magnetopause, and Wild et al. $(2001,2003)$ identified FTE perturbations in the magnetic field at Cluster, followed by pulsed ionospheric flow in both hemispheres, extending over several hours in MLT. Milan et al. (2000) have also seen FTE auroral signatures extending across $7 \mathrm{~h}$ of MLT. On the other hand, Marchaudon et al. (2004a) have reported a more localized FTE signature in the ionosphere $(30-60 \mathrm{~km}$ east-west, and $300 \mathrm{~km}$ northsouth) with a reasonably good match of the velocities, both at Cluster and in the ionosphere. This size is in excellent agreement with the case we present, where the flow channel is from 30 to $50 \mathrm{~km}$ wide in the north-south direction and at least $400 \mathrm{~km}$ in the east-west direction. However, our event is elongated in the east-west direction instead of the northsouth direction, an orientation that appears to be consistent with other studies (e.g. Provan et al., 1998; Milan et al., 2000; McWilliams et al., 2001). Nevertheless, these studies indicate an elongated rather than a circular FTE cross section, and this has recently been confirmed by an in-situ Cluster study (Sonnerup et al., 2004).

Sonnerup et al. (2004) also estimated that the magnetic flux associated by the FTE flux tube on which they report was $2 \mathrm{MWb}$. By multiplying the area of the flow channel $(50 \mathrm{~km} \times 400 \mathrm{~km})$ with the magnetic field strength $\left(5 \times 10^{4} \mathrm{nT}\right)$ an estimate for our FTE event gives us around $1 \mathrm{MWb}$, but our estimate should only be regarded as a minimum. It is quite likely that FC4 in Fig. 3 extended beyond the ESR field-of-view in the east-west direction. It should also be noted that it can make a difference if one chooses to use the optical PMAF signature instead of the associated flow channel to determine the dimensions of an FTE flux tube. It is important to notice that the upward Birkeland current of the PMAF is associated with both 557.7-nm and 630.0-nm auroral emissions. Unfortunately, early studies (e.g. Lockwood et al., 1989a, 1989b) postulated that the 557.7-nm emissions marked the region of the upward Birkeland current associated with the FTE, whilst the 630.0-nm emissions were present over a large region, suggesting bulk injection of soft particles over the entire area of newly-opened flux. However, this suggestion was based on observations with a first generation all-sky TV camera that did not have the capability to resolve fine structure. Furthermore, optical data is, to a larger degree, dependent on the sensitivity threshold of the camera; a more sensitive camera may find the PMAF structure to be wider. The ESR data in Fig. 3 also indicate that the FTE flow channel occupied a larger area than the PMAF. It should also be noted that the spatial resolution of the radar data is an essential factor to be able to resolve the flow channels in Fig. 3. If the footprint of a relatively narrow FTE flux tube falls at the edge between two radar range gates, the flow channel may completely disappear (as each radar range gate contains flow filaments in opposite directions). The same is true if a single radar range gate is larger than the width of the flow channel. In other words, if the spatial resolution is poor, one may be misled to conclude that FTEs are a minor contributor to the polar cap potential, or that pulsed reconnection is of less importance than it really is. It has also been suggested by Pinnock et al. (1995), Lockwood et al. (1995) and Milan et al. (2000) that several FTEs can occur at the edge of the cusp over several hours in MLT, and that FTEs in this manner can be a significant contributor to the cross-polar cap potential. It is clear that the spatial resolution of the measurements is a very critical factor, and with poor resolution the contribution from FTEs may be underestimated.

We can also estimate the duration of the ionospheric signature of this particular FTE. Using the location of the $30 \mathrm{keV}$ electron trapping boundary in Fig. 7 as a marker for the transition between open and closed field lines (e.g. as in Moen et al., 1996; Oksavik et al., 2000) gives an open-closed field line boundary at $73.5^{\circ}$ magnetic latitude around 10:20 UT. Consequently, the NOAA data indicate that the cusp aurora was residing entirely on open field lines (both the main eastwest elongated arc and the PMAF located further poleward). The structured plasma flow (FC1 to FC7) in Fig. 3 was also observed north of the open-closed field line boundary. These flow channels seemed to head poleward through the ESR field-of-view, one after the other. FC4 was the most distinct flow channel with prominent reverse flow on both sides, and a PMAF on its poleward side, as identified by Oksavik et al. (2004a). A close inspection of the ESR data shows that FC4 first appeared around 09:56 UT with its equatorward 


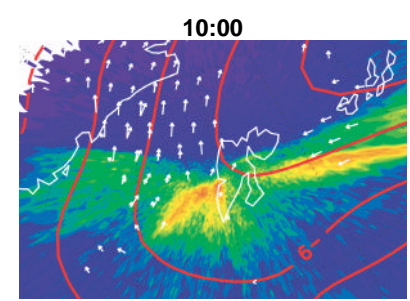

10:02

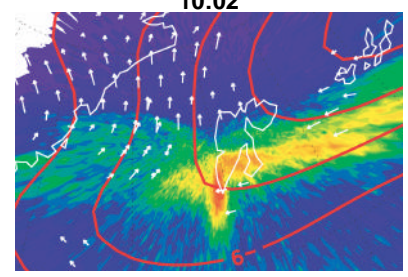

10:04

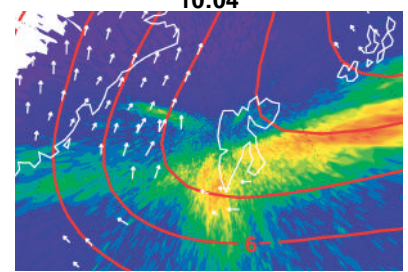

10:06
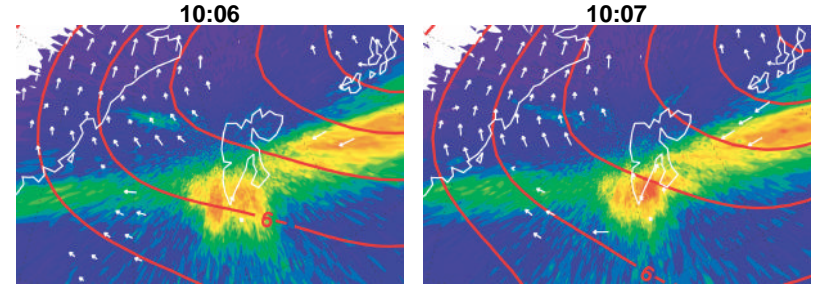

Fig. 8. Sequence of all-sky images of the 630-nm cusp aurora overlaid with the map-potential model output (red contours) and measured flow vectors (white arrows) from the SuperDARN radar network.

edge at $74.3^{\circ}$ magnetic latitude near 12:00 MLT. Around 10:04-10:05 UT the flow channel was located poleward of 77.3-77.5 magnetic latitude. The very last remnants of FC4 left the ESR field-of-view around 10:11 UT, just north of $78.2^{\circ}$ magnetic latitude. This is also confirmed by the DMSP F13 observations (Fig. 6) with the guidance of the all-sky camera images (Fig. 4). Around 10:11 UT DMSP F13 detected a narrow region of sunward flow (Fig. 6e) surrounded by anti-sunward flow. From the all-sky images it is clear that this small-scale twin vortex pattern is indeed the FC4 flow channel that the ESR was tracking and is located very close to the fossil PMAF flux tube. Consequently, this gives a total duration of the ionospheric FTE signature of at least 15 minutes and a poleward motion of at least $4^{\circ}$ in latitude, corresponding to a phase velocity of around $500 \mathrm{~m} / \mathrm{s}$. This number is also consistent with SuperDARN plasma convection data and the PMAF motion presented in Fig. 8. Shown with white arrows are measured flow vectors by the Finland and Iceland East SuperDARN radars, and overlaid with red is the contour output from the mappotential model (Ruohoniemi and Baker, 1998), where the model suggests a total polar cap potential of $60-70 \mathrm{kV}$. The PMAF is seen in the left half (western part) of the image frames drifting into the polar cap in a direction, and with a velocity, similar to the background convection. Near the PMAF SuperDARN observed a poleward velocity of around $500 \mathrm{~m} / \mathrm{s}$, also consistent with the convection seen by DMSP F13. It should be noted that in Fig. 8 there are two vectors at a few locations because (1) one minute of data was used to generate the vectors, (2) the radars were running a scan, and (3) at some locations there are two measurements of the line-of-sight velocity for one of the radars.

This observation suggests that the FTE signature convects with the large-scale flow (Denig et al., 1993). The ionospheric footprint of an FTE, i.e. the small twin-vortex flow feature that the Southwood (1987) model predicts, is not just a local disturbance near the convection reversal boundary. As time evolves and the twin-vortex flow feature propagates poleward into the polar cap, this small feature continues to disturb the background convection, at least on a spatial scale of a few tens of kilometers. Our observations also demonstrate that the flow disturbance from such individual FTEs may even be present in the local convection within the polar cap several minutes after the auroral intensity has faded below the detection threshold of a camera. It is well known that on a gross scale the dayside convection is highly variable near the convection reversal boundary, but in the polar cap the convection is thought to be mainly anti-sunward (e.g. Cowley and Lockwood, 1992; Shepherd et al., 2003). This is consistent with the appearance of FTEs; however, our comprehensive data set shows that if the spatial resolution of the measurements is sufficient, one may observe that the unique FTE flow signatures persist a long time after the FTE flux tube opened. It is also obvious that the observational geometry of the ESR (3-min scan looking west) is ideal to be able to monitor the temporal evolution of these flow channels. There is also an element of good fortune involved in the timing of the scans tracking FC4, since the radar beam visited the flow channel around 10:03:30-10:05:30 UT when the PMAF was at its brightest. The second element of good fortune is the location of the DMSP F13 spacecraft trajectory (Fig. 6), confirming the persistence of the FTE flow pattern. It is also interesting to note that DMSP F13 revealed a 30$40 \mathrm{~km}$ wide channel with net sunward flow associated with the FTE. This shows that even if the gross convection pattern appears to be anti-sunward in the polar cap during periods of southward IMF, individual FTEs are capable of driving the plasma sunward in localized areas of a few tens of kilometers. The FTE vortex feature might be thought of as spinning about a centre of gravity which moves antisunward. That the DMSP drift shows sunward flow around 10:11 UT is because the plasma is vortexing faster than the centre of motion, and so for a part of its vortex trajectory the plasma moves faster towards the Sun than the vortex centre is moving away from the Sun.

FTEs may also be the driver for the region 0 current system in the cusp. The Southwood (1987) model describes how a pair of Birkeland currents will be flowing at the edges of 
an individual FTE flow channel. Lockwood et al. (1993) have also predicted that Birkeland currents will be flowing at the boundaries of successive FTEs. In agreement with the Southwood FTE model a recent paper by Marchaudon et al. (2004b) presents data from the Ørsted spacecraft of field-aligned currents on each side of a flow channel seen by SuperDARN. Our data set is also indicative of a fine-scale current system surrounding FC4; an upward current on the poleward side (consistent with the location of the PMAF), and a downward current on the equatorward side (consistent with the absence of electron aurora). Birkeland currents and the associated current carriers in the cusp region represent an area that is not well understood (Yamauchi et al., 1998). Iijima and Potemra (1976a,b) used magnetic field perturbations from the Triad spacecraft to study the large-scale current systems in the high-latitude ionosphere, and they introduced the region 1, region 2 and cusp currents. A decade later Erlandson et al. (1988) and Bythrow et al. (1988) suggested that the cusp current should be renamed the mantle current, due to the fact that it is usually observed on field lines that map to the plasma mantle poleward of the most intense magnetosheath-like electron precipitation. This is also confirmed by Stauning et al. (2001), using high-resolution measurements from the Danish Ørsted satellite, which suggests that the region 1 current is located in the LLBL equatorward of the cusp (Woch et al., 1993). In a recent paper Oksavik et al. (2004b) combined observations from the FAST spacecraft with ground-based optical images from Svalbard, and they found counterstreaming electrons associated with stepped cusp signatures and southward IMF cusp aurora. Furthermore, the cusp ion steps were associated with thin sheets of fine-scale field-aligned currents flowing near the edges of the ion steps, consistent with the predictions of Lockwood et al. (2001) for pulsed reconnection during periods with large IMF $B_{y}$. All these studies in fact appear to relate the region 0 or cusp/mantle currents to FTEs. In Fig. 9 we present a sketch showing the location of these fieldaligned currents relative to the polar cap boundary and the aurora for the case studied in this paper (Northern Hemisphere, IMF $B_{y}>0$ and $B_{z}<0$ ). The open-closed field line boundary is indicated with a dashed line just equatorward of the east-west elongated background cusp aurora, consistent with the post-noon region 1 current flowing out of the ionosphere. The perimeter of the FTE flux tube (i.e. FC4 in Fig. 3) is encircled with a solid line. Located on the poleward edge of the FTE flow channel are the PMAF and the associated FTE1 current (flowing out of the ionosphere). On the equatorward side is the associated FTE2 current (flowing into the ionosphere). Whilst the region 1 current system is at a fixed location with respect to the open-closed field line boundary and the convection reversal, the FTE current system moves with the background convection into the polar cap as a "fossil" signature of FTEs. The westward and poleward motion of the FTE current system described in this paper is indicated with a green arrow. The FTE current system is consistent with the Southwood (1987) flux transfer model, and represents the temporal and spatial variability of the region

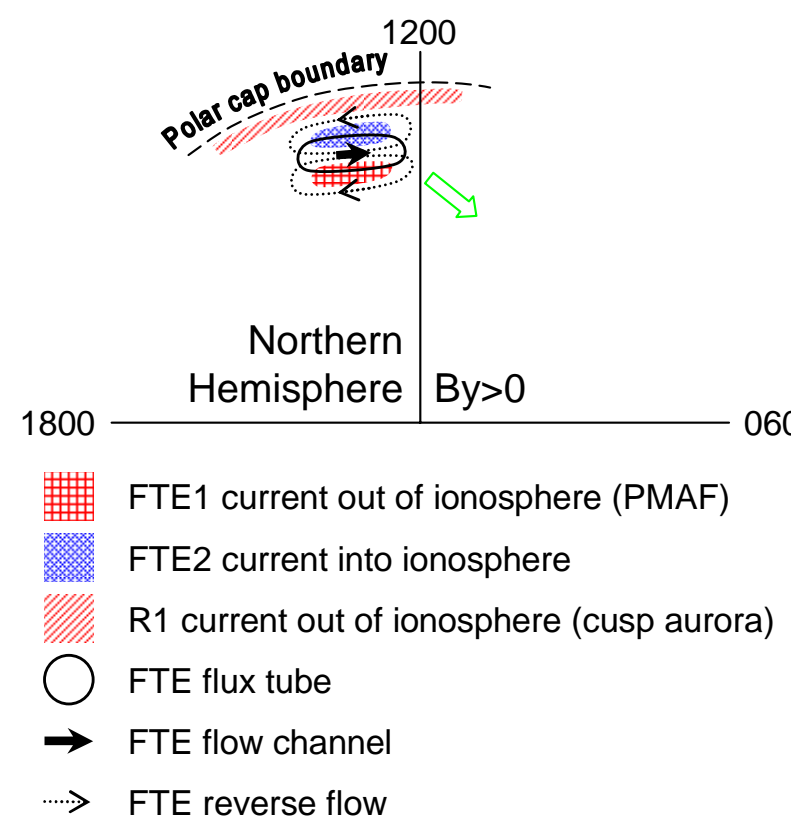

Fig. 9. Sketch showing the location of the FTE currents (former region 0 ) and the post-noon region 1 current relative to the polar cap boundary and the aurora for the Northern Hemisphere IMF $B_{y}>0$ and $B_{z}<0$ case studied in this paper. The perimeter of the FTE flux tube is encircled with a solid line, and the FTE current system is moving westward and poleward with the background convection, as indicated with the green arrow.

0 current. High-resolution radar sweeps, as presented here, provide the only means to map the spatial and temporal evolution of individual FTE flow disturbances, and hence the spatial distribution and motion of the associated current system. When we have achieved such a detailed observation of an event class reported in the literature for over two decades, we find it adequate to introduce a new term - FTE currents that should be used strictly when describing such individual events. In the past most observations have been snapshots from passing spacecraft, giving only a spatial view of this highly temporal-varying poleward-moving small-scale current system.

\section{Conclusion}

In this paper we have presented a comprehensive set of observations of the ionospheric footprint of an FTE using the EISCAT Svalbard radar, the SuperDARN HF radar network, ground-based optics, and three low-altitude polar orbiting spacecraft. During an interval of southward IMF the EISCAT Svalbard radar was tracking a train of narrow flow channels drifting into the polar cap. One of these flow channels was measured with unprecedented completeness. It was surrounded by reverse flow and joined by a PMAF on its poleward edge, consistent with a small-scale twin vortex flow pattern and field-aligned currents on the sides of the flow channel, a downward current on the equatorward side, and 
an upward current on the poleward side (Southwood, 1987; Oksavik et al., 2004a). The high spatial resolution of the observations made it possible to track this particular flow channel and its persistence in time and space from where it was launched (equatorward of the cusp aurora) until it left the field-of-view some 15 minutes later and $4^{\circ}$ of latitude deeper into the polar cap. On a gross scale the convection pattern across the polar cap may look like a two-cell pattern, however, on spatial scales of a few tens of kilometers one may see flow distortions due to individual FTEs superimposed onto the background convection. The dimensions of the flow channel indicate that the magnetic flux of the event was at least $1 \mathrm{MWb}$. We also suggest that the Birkeland current filaments often seen by low-altitude spacecraft in the cusp/mantle are really associated with FTEs in progress. In order to put these high-resolution observations in contrast to classical region 0 or cusp/mantle currents inferred from satellites, we suggest the new term - FTE currents - to describe the Birkeland currents of individual flux transfer events.

Acknowledgements. EISCAT is an international association supported by Finland (SA), France (CNRS), Germany (MPG), Japan (NIPR), Norway (NFR), Sweden (NFR), and the United Kingdom (PPARC). CUTLASS is supported by the UK Particle Physics and Astronomy Research Council (PPARC), the Swedish Institute for Space Physics, and the Finnish Meteorological Institute in Helsinki. We thank the ACE Science Center and the ACE MAG and SWEPAM instrument teams for providing solar wind data from the ACE spacecraft. Financial support has been provided by the Norwegian Research Council, AFOSR task 2311AS, and NSF Grant ATM-0418101.

Topical Editor in chief thanks J. Rae and another referee for their help in evaluating this paper.

\section{References}

Baker, K. B., Dudeney, J. R., Greenwald, R. A., Pinnock, M., Newell, P. T., Rodger, A. S., Mattin, N., and Meng, C.-I.: HF radar signatures of the cusp and low-latitude boundary layer, J. Geophys. Res., 100, 7671-7696, 1995.

Bythrow, P. F., Potemra, T. A., Erlandson, R. E., Zanetti, L. J., and Klumpar, D. M.: Birkeland currents and charged particles in the high-latitude pre-noon region: A new interpretation, J. Geophys. Res., 93, 9791-9803, 1988.

Carlson, H. C., Oksavik, K., Moen, J., van Eyken, A. P., and Guio, P.: ESR mapping of polar-cap patches in the dark cusp, Geophys. Res. Lett., 29 (10), 1386, doi:10.1029/2001GL014087, 2002.

Carlson, H. C., Oksavik, K., Moen, J., and Pedersen, T.: Ionospheric patch formation: Direct measurements of the origin of a polar cap patch, Geophys. Res. Lett., 31 (8), L08806, doi:10.1029/2003GL018166, 2004.

Chisham, G., Pinnock, M., and Rodger, A. S.: Poleward-moving HF radar flow bursts in the cusp: Transient changes in flow speed or direction?, Geophys. Res. Lett., 27, 919-922, 2000.

Chiu, M. C., Von-Mehlem, U. I., Willey, C. E., Betenbaugh, T. M., Maynard, J. J., Krein, J. A., Conde, R. F., Gray, W. T., Hunt Jr., J. W., Mosher, L. E., McCullough, M. G., Panneton, P. E., Staiger, J. P., and Rodberg, E. H.: ACE spacecraft, Space Sci. Rev., 86, 257-284, 1998.
Cowley, S. W. H. and Lockwood, M.: Excitation and decay of solar wind-driven flows in the magnetosphere-ionosphere system, Ann. Geophys., 10, 103-115, 1992.

Davies, J. A., Lester, M., Milan, S. E., and Yeoman, T. K.: A comparison of velocity measurements from the CUTLASS Finland radar and the EISCAT UHF system, Ann. Geophys., 17, 892902, 1999,

SRef-ID: 1432-0576/ag/1999-17-892.

Davies, J. A., Yeoman, T. K., Lester, M., and Milan, S. E.: A comparison of F-region ion velocity observations from the EISCAT Svalbard and VHF radars with irregularity drift velocity measurements from the CUTLASS Finland HF radar, Ann. Geophys., 18, 589-594, 2000,

\section{SRef-ID: 1432-0576/ag/2000-18-589.}

Davies, J. A., Yeoman, T. K., Rae, I. J., Milan, S. E., Lester, M., Lockwood, M., and McWilliams, A.: Ground-based observations of the auroral zone and polar cap ionospheric responses to dayside transient reconnection, Ann. Geophys., 20, 781-794, 2002,

SRef-ID: 1432-0576/ag/2002-20-781.

Denig, W. F., Burke, W. J., Maynard, N. C., Rich, F. J., Jacobsen, B., Sandholt, P. E., Egeland, A., Leontjev, S., and Vorobjev, V. G.: Ionospheric signatures of dayside magnetopause transients: A case study using satellite and ground measurements, J. Geophys. Res., 98, 5969-5980, 1993.

Dungey, J.W.: Interplanetary magnetic field and the auroral zones, Phys. Rev. Lett., 6, 47-49, 1961.

Erlandson, R. E., Zanetti, L. J., Potemra, T. A., Bythrow, P. F., and Lundin, R.: IMF By dependence of region 1 Birkeland currents near noon, J. Geophys. Res., 93, 9804-9814, 1988.

Evans, D. S. and Greer, M. S.: Polar orbiting environmental satellite space environment monitor - 2: Instrument descriptions and archive data documentation, NOAA Technical Memorandum OAR SEC-93, Space Environment Center, Boulder, Colorado, 2000.

Glassmeier, K.-H. and Stellmacher, M.: Mapping flux transfer events to the ionosphere, Adv. Space Res., 18(8), 151-160, 1996.

Goertz, C. K., Nielsen, E., Korth, A., Glassmeier, K. H., Haldoupis, C., Hoeg, P., and Hayward, D.: Observations of a possible ground signature of flux transfer events, J. Geophys. Res., 90, 4069-4078, 1985.

Greenwald, R. A., Baker, K. B., Hutchins, R. A., and Hanuise, C.: An HF phased-array radar for studying small-scale structure in the high-latitude ionosphere, Radio Science, 20, 63-79, 1985.

Greenwald, R. A., Baker, K. B., Dudeney, J. R., Pinnock, M., Jones, T. B., Thomas, E. C., Villain, J.-P., Cerisier, J.-C., Senior, C., Hanuise, C., Hunsucker, R. D., Sofko, G., Koehler, J., Nielsen, E., Pellinen, R., Walker, A. D. M., Sato, N., and Yamagishi, H.: DARN/SuperDARN a global view of the dynamics of highlatitude convection, Space Sci. Rev., 71, 761-796, 1995.

Haerendel, G., Paschmann, G., Sckopke, N., Rosenbauer, H., and Hedgecock, P. C.: The frontside boundary layer of the magnetosphere and the problem of reconnection, J. Geophys. Res., 83, 3195-3216, 1978.

Hanuise, C., Villain, J. P., Gresillon, D., Cabrit, B., Greenwald, R. A., and Baker, K. B.: Interpretation of HF radar ionospheric Doppler spectra by collective wave scattering theory, Ann. Geophys., 11, 29-39, 1993.

Hardy, D. A., Schmidt, L. K., Gussenhoven, M. S., Marshall, F. J., Yeh, H. C., Schumaker, T. L., Huber, A., and Pantazis, J.: Precipitating electron and ion detectors (SSJ/4) for the block, 5D/Flights 4-10 DMSP satellites: Calibration and data 
presentation, Rep. AFGL-TR-84-0317, Air Force Geophys. Lab., Hanscom Air Force Base, Mass., 1984.

Iijima, T. and Potemra, T. A.: The amplitude distribution of field aligned currents at northern high latitudes observed by Triad, J. Geophys. Res., 81, 2165-2174, 1976a.

Iijima, T. and Potemra, T. A.: Field-aligned currents in the dayside cusp observed by Triad, J. Geophys. Res., 81, 5971-5979, 1976 b.

Lockwood, M., Sandholt, P. E., and Cowley, S. W. H.: Dayside auroral activity and magnetic flux transfer from the solar wind, Geophys. Res. Lett., 16, 33-36, 1989a.

Lockwood, M., Sandholt, P. E., Cowley, S. W. H., and Oguti, T.: Interplanetary magnetic field control of dayside auroral activity and the transfer of momentum across the dayside magnetopause, Planet. Space Sci., 37, 1347-1365, 1989 b.

Lockwood, M., Carlson Jr., H. C., and Sandholt, P. E.: Implications of the altitude of transient 630-nm dayside auroral emissions, J. Geophys. Res., 98, 15 571-15 587, 1993.

Lockwood, M., Cowley, S. W. H., Smith, M. F., Rijnbeek, R. P., and Elphic, R. C.: The contribution of flux transfer events to convection, Geophys. Res. Lett., 22, 1185-1188, 1995.

Lockwood, M., Milan, S. E., Onsager, T., Perry, C. H., Scudder, J. A., Russell, C. T., and Brittnacher, M.: Cusp ion steps, field aligned currents and poleward moving auroral forms, J. Geophys. Res., 106, 29555-29569, 2001.

Mandea, M. and S. Macmillan: International Geomagnetic Reference Field - the eighth generation, Earth Planets Space, 52, 1119-1124, 2000.

Marchaudon, A., Cerisier, J.-C., Bosqued, J.-M., Dunlop, M. W., Wild, J. A., Décréau, P. M. E., Förster, M., Fontaine, D., and Laakso, H.: Transient plasma injections in the dayside magnetosphere: one-to-one correlated observations by Cluster and SuperDARN, Ann. Geophys., 22, 141-158, 2004a,

SRef-ID: 1432-0576/ag/2004-22-141.

Marchaudon, A., Cerisier, J.-C., Greenwald, R. A., and Sofko, G. J.: Electrodynamics of a flux transfer event: Experimental test of the Southwood model, Geophys. Res. Lett., 31, L09809, doi:10.1029/2004GL019922, 2004b.

McComas, D. J., Bame, S. J., Barker, P., Feldman, W. C., Phillips, J. L., Riley, P., and Griffee, J. W.: Solar Wind Electron Proton Alpha Monitor (SWEPAM) for the Advanced Composition Explorer, Space Sci. Rev., 86, 563-612, 1998.

McWilliams, K. A., Yeoman, T. K., and Provan, G.: A statistical survey of dayside pulsed ionospheric flows as seen by the CUTLASS Finland HF radar, Ann. Geophys., 18, 445-453, 2000,

\section{SRef-ID: 1432-0576/ag/2000-18-445.}

McWilliams, K. A., Yeoman, T. K., and Cowley, S. W. H.: Twodimensional electric field measurements in the ionospheric footprint of a flux transfer event, Ann. Geophys., 18, 1584-1598, 2001,

\section{SRef-ID: 1432-0576/ag/2000-18-1584}

McWilliams, K. A., Sofko, G. J., Yeoman, T. K., Milan, S. E., Sibeck, D. G., Nagai, T., Mukai, T., Coleman, I. J., Hori, T., and Rich, F. J.: Simultaneous observations of magnetopause flux transfer events and of their associated signatures at ionospheric altitudes, Ann. Geophys., 22, 2181-2199, 2004,

SRef-ID: 1432-0576/ag/2004-22-2181.

Milan, S. E., Yeoman, T. K., Lester, M., Thomas, E. C., and Jones, T. B.: Initial backscatter occurrence statistics from the CUTLASS HF radars, Ann. Geophys., 15, 703-718, 1997, SRef-ID: 1432-0576/ag/1997-15-703.

Milan, S. E., Yeoman, T. K., and Lester, M.: The dayside auroral zone as a hard target for coherent HF radars, Geophys. Res. Lett.,
25, 3717-3720, 1998.

Milan, S. E., Lester, M., Cowley, S. W. H., Moen, J., Sandholt, P. E., and Owen, C. J.: Meridian-scanning photometer observations of the cusp: a case study, Ann. Geophys., 17, 159-172, 1999a, SRef-ID: 1432-0576/ag/1999-17-159.

Milan, S. E., Yeoman, T. K., Lester, M., Moen, J., and Sandholt, P. E.: Post-noon two-minute period pulsating aurora and their relationship to the dayside convection pattern, Ann. Geophys., 17, 877-891, 1999b,

SRef-ID: 1432-0576/ag/1999-17-877.

Milan, S. E., Lester, M., Cowley, S. W. H., and Brittnacher, M.: The convection and auroral response to a southward turning of the IMF: POLAR UVI, CUTLASS, and IMAGE signatures of transient magnetic flux transfer at the magnetopause, J. Geophys. Res., 105, 15 741-15 755, 2000.

Moen, J., Sandholt, P. E., Lockwood, M., Denig, W. F., Løvhaug, U. P., Lybekk, B., Egeland, A., Opsvik, D., and Friis-Christensen, E.: Events of enhanced convection and related dayside auroral activity, J. Geophys. Res., 100, 23 917-23 934, 1995.

Moen, J., Evans, D., Carlson, H. C., and Lockwood, M.: Dayside moving auroral transients related to LLBL dynamics, Geophys. Res. Lett., 23, 3247-3250, 1996.

Moen, J., van Eyken, A. P., and Carlson, H. C.: EISCAT Svalbard Radar observations of ionospheric plasma dynamics in relation to dayside auroral transients, J. Geophys. Res., 106, 21 453-21 461, 2001a.

Moen, J., Carlson, H. C., Milan, S. E., Shumilov, N., Lybekk, B., Sandholt, P. E., and Lester, M., On the collocation between dayside auroral activity and coherent HF radar backscatter, Ann. Geophys., 18, 1531-1549, 2001b.

Neudegg, D. A., Yeoman, T. K., Cowley, S. W. H., Provan, G., Haerendel, G., Baumjohann, W., Auster, U., Fornacon, K.-H., Georgescu, E., and Owen, C. J.: A flux transfer event observed at the magnetopause by the Equator-S spacecraft and in the ionosphere by the CUTLASS HF radar, Ann. Geophys., 17, 707-711, 1999 ,

\section{SRef-ID: 1432-0576/ag/1999-17-707.}

Neudegg, D. A., Cowley, S. W. H., Milan, S. E., Yeoman, T. K., Lester, M., Provan, G., Haerendel, G., Baumjohann, W., Nikutowski, B., Büchner, J., Auster, U., Fornacon, K.-H., and Georgescu, E.: A survey of magnetopause FTEs and associated flow bursts in the polar ionosphere, Ann. Geophys., 18, 416-435, 2000 ,

\section{SRef-ID: 1432-0576/ag/2000-18-416}

Newell, P. T. and Meng, C.-I.: Mapping the dayside ionosphere to the magnetosphere according to particle-precipitation characteristics, Geophys. Res. Lett., 19 (6): 609-612, 1992.

Oksavik, K., Søraas, F., Moen, J., and Burke, W. J.: Optical and particle signatures of magnetospheric boundary layers near magnetic noon: Satellite and ground-based observations, J. Geophys. Res., 105, 27 555-27 568, 2000.

Oksavik, K., Moen, J., and Carlson, H. C.: High-resolution observations of the small-scale flow pattern associated with a poleward moving auroral form in the cusp, Geophys. Res. Lett., 31(11), L11807, doi:10.1029/2004GL019838, 2004a.

Oksavik, K., Søraas, F., Moen, J., Pfaff, R., Davies, J. A., and Lester, M.: Simultaneous optical, CUTLASS HF radar, and FAST spacecraft observations: Signatures of boundary layer processes in the cusp, Ann. Geophys., 22(2), 511-525, 2004b, SRef-ID: 1432-0576/ag/2004-22-511.

Pinnock, M., Rodger, A. S., Dudeney, J. R., Baker, K. B., Newell, P. T., Greenwald, R. A., and Greenspan, M. E.: Observations of an 
enhanced convection channel in the cusp ionosphere, J. Geophys. Res., 98, 3767-3776, 1993.

Pinnock, M., Rodger, A. S., Dudeney, J. R., Rich, F., and Baker, K. B.: High spatial and temporal resolution observations of the ionospheric cusp, Ann. Geophys., 13, 919-925, 1995,

SRef-ID: 1432-0576/ag/1995-13-919.

Provan, G. and T. K. Yeoman: Statistical observations of the MLT, latitude and size of pulsed ionospheric flows with the CUTLASS Finland radar, Ann. Geophys., 17, 855-867, 1999,

SRef-ID: 1432-0576/ag/1999-17-855.

Provan, G., Yeoman, T. K., and Milan, S. E.: CUTLASS Finland radar observations of the ionospheric signature of flux transfer events and the resulting plasma flow, Ann. Geophys., 16, 14111422, 1998,

SRef-ID: 1432-0576/ag/1998-16-1411.

Provan, G., Milan, S. E., Lester, M., Yeoman, T. K., and Khan, H.: Simultaneous observations of the ionospheric footprint of flux transfer events and dispersed ion signatures, Ann. Geophys., 20, 281-287, 2002,

SRef-ID: 1432-0576/ag/2002-20-281.

Rae, I. J., Fenrich, F. R., Lester, M., McWilliams, K. A., and Scudder, J. D.: Solar wind modulation of cusp particle signatures and their associated ionospheric flows, J. Geophys. Res., 109, A03223, doi:10.1029/2003JA010188, 2004.

Rich, F. J. and Hairston, M.: Large-scale convection patterns observed by DMSP, J. Geophys. Res., 99, 3827-3844, 1994.

Ruohoniemi, J. M., Greenwald, R. A., Baker, K. B., Villain, J. P., and McCready, M. A.: Drift motions of small-scale irregularities in the high-latitude F region: An experimental comparison with plasma drift motions, J. Geophys. Res., 92, 4553-4564, 1987.

Ruohoniemi, J. M. and Baker, K. B.: Large-scale imaging of highlatitude convection with Super Dual Auroral Radar Network HF radar observations, J. Geophys. Res., 103, 20 797-20 811, 1998.

Russell, C. T.: The configuration of the magnetosphere, in Critical Problems of Magnetospheric Physics, (Ed.) Dyer, E. R., 1-16, IUCSTP Secretariat, c/o National Academy of Sciences, Washington, D. C., 1972.

Russell, C. T. and Elphic, R. C.: Initial ISEE magnetometer results: magnetopause observations, Space Sci. Rev., 22, 681-715, 1978.

Russell, C. T. and Elphic, R. C.: ISEE observations of flux transfer events at the dayside magnetopause, Geophys. Res. Lett., 6, 3336, 1979.

Sandholt, P. E., Lockwood, M., Oguti, T., Cowley, S. W. H., Freeman, K. S. C., Lybekk, B., Egeland, A., and Willis, D. M.: Midday auroral breakup events and related energy and momentum transfer from the magnetosheath, J. Geophys. Res., 95, 10391060, 1990.

Sandholt, P. E., Moen, J., Opsvik, D., Denig, W. F., and Burke, W. J.: Auroral event sequence at the dayside polar cap boundary: signature of time-varying solar wind-magnetosphere-ionosphere coupling, Adv. Space. Res., 13, (4)7-15, 1993.

Saunders, M. A., Russell, C. T., and Sckopke, N.: Flux transfer events: scale size and interior structure, Geophys. Res. Lett., 11, 131-134, 1984.

Shepherd, S. G., Ruohoniemi, J. M., and Greenwald, R. A.: Direct measurements of the ionospheric convection variability near the cusp/throat, Geophys. Res. Lett., 30(21), 2109, doi:10.1029/2003GL017668, 2003.
Smith, C. W., L'Heureux, J., Ness, N. F., Acuña ,M. H., Burlaga, L. F., and Scheifele, J.: The ACE magnetic fields experiment, Space Sci. Rev., 86, 613-632, 1998.

Sonnerup, B. U. Ö., Hasegawa, H., and Paschmann, G., Anatomy of a flux transfer event seen by Cluster, Geophys. Res. Lett., 31, L11803, doi:10.1029/2004GL020134, 2004.

Southwood, D. J.: Theoretical aspects of ionospheremagnetosphere-solar wind coupling, Adv. Space Res., 5(4), 7-14, 1985.

Southwood, D. J.: The ionospheric signature of flux transfer events, J. Geophys. Res., 92, 3207-3213, 1987.

Southwood, D. J. and Hughes, W. J.: Theory of hydromagnetic waves in the magnetosphere, Space Sci. Rev., 35, 301-366, 1983.

Stauning, P., Primdahl, F., Watermann, J., and Rasmussen, O.: IMF By-related cusp currents observed from the Ørsted satellite and from ground, Geophys. Res. Lett., 28, 99-102, 2001.

Thorolfsson, A., Cerisier, J.-C., Lockwood, M., Sandholt, P. E., Senior, C., and Lester, M.: Simultaneous optical and radar signatures of poleward-moving auroral forms, Ann. Geophys., 18, 1054-1066, 2000,

\section{SRef-ID: 1432-0576/ag/2000-18-1054.}

van Eyken, A. P., Rishbeth, H., Willis, D. M., and Cowley, S. W. H.: Initial EISCAT observations of plasma convection at invariant latitudes $70^{\circ}-77^{\circ}$, J. Atm. Terr. Phys, 46, 635-641, 1984.

Villain, J. P., Caudal, G., and Hanuise, C.: A SAFARI-EISCAT comparison between the velocity of $F$ region small-scale irregularities and the ion drift, J. Geophys. Res., 90, 8433-8443, 1985.

Wild, J. A., Cowley, S. W. H., Davies, J. A., Khan, H., Lester, M., Milan, S. E., Provan, G., Yeoman, T. K., Balogh, A., Dunlop, M. W., Fornacon, K.-H., and Georgescu, E.: First simultaneous observations of flux transfer events at the high-latitude magnetopause by the Cluster spacecraft and pulsed radar signatures in the conjugate ionosphere by the CUTLASS and EISCAT radars, Ann. Geophys., 19, 1491-1508, 2001,

SRef-ID: 1432-0576/ag/2001-19-1491.

Wild, J. A., Milan, S. E., Cowley, S. W. H., Dunlop, M. W., Owen, C. J., Bosqued, J. M., Taylor, M. G. G. T., Davies, J. A., Lester, M., Sato, N., Yukimatu, A. S., Fazakerley, A. N., Balogh, A., and Rème, H.: Coordinated interhemispheric SuperDARN radar observations of the ionospheric response to flux transfer events observed by the Cluster spacecraft at the high-latitude magnetopause, Ann. Geophys., 21, 1807-1826, 2003,

SRef-ID: 1432-0576/ag/2003-21-1807.

Woch, J., Yamauchi, M., Lundin, R., Potemra, T. A., and Zanetti, L. J.: The low-latitude boundary layer at mid-altitudes: Relation to large-scale Birkeland currents, Geophys. Res. Lett., 20, 22512254, 1993.

Yamauchi, M., Lundin, R., Eliasson, L., Ohtani, S., and Clemmons, J. H.: Relationship between large-, meso-, and small-scale field aligned currents and their current carriers, in: Polar Cap Boundary Phenomena, (Eds.) Moen, J., Egeland, A., and Lockwood, M., 173, Kluwer Acad., Norwell, Mass., 1998. 